NBER WORKING PAPER SERIES

\title{
MACROECONOMIC EFFECTS OF MEDICARE
}

\author{
Juan Carlos Conesa \\ Daniela Costa \\ Parisa Kamali \\ Timothy J. Kehoe \\ Vegard M. Nygard \\ Gajendran Raveendranathan \\ Akshar Saxena \\ Working Paper 23389 \\ http://www.nber.org/papers/w23389 \\ NATIONAL BUREAU OF ECONOMIC RESEARCH \\ 1050 Massachusetts Avenue \\ Cambridge, MA 02138 \\ May 2017
}

This project was supported by the National Institutes of Health (NIH Grant No. 5R01AG048037-02). We thank participants at the 2015 Macroeconomics of Population Aging Workshop at Harvard T.H. Chan School of Public Health, the Aging and Macroeconomics meeting at the 2016 Barcelona GSE Summer Forum, the Macro Public Finance Group meeting at the 2016 NBER Summer Institute, and two anonymous referees for helpful comments. The views expressed herein are those of the authors and not necessarily those of the Federal Reserve Bank of Minneapolis, the Federal Reserve System, or the National Bureau of Economic Research. The data and computer code used here can be found in the supplementary materials available at www.econ.umn.edu/ tkehoe.

NBER working papers are circulated for discussion and comment purposes. They have not been peer-reviewed or been subject to the review by the NBER Board of Directors that accompanies official NBER publications.

(C) 2017 by Juan Carlos Conesa, Daniela Costa, Parisa Kamali, Timothy J. Kehoe, Vegard M. Nygard, Gajendran Raveendranathan, and Akshar Saxena. All rights reserved. Short sections of text, not to exceed two paragraphs, may be quoted without explicit permission provided that full credit, including $\odot$ notice, is given to the source. 
Macroeconomic Effects of Medicare

Juan Carlos Conesa, Daniela Costa, Parisa Kamali, Timothy J. Kehoe, Vegard M. Nygard, Gajendran Raveendranathan, and Akshar Saxena

NBER Working Paper No. 23389

May 2017

JEL No. E21,E62,H51,I13

\section{ABSTRACT}

This paper develops an overlapping generations model to study the macroeconomic effects of an unexpected elimination of Medicare. We find that a large share of the elderly respond by substituting Medicaid for Medicare. Consequently, the government saves only 46 cents for every dollar cut in Medicare spending. We argue that a comparison of steady states is insufficient to evaluate the welfare effects of the reform. In particular, we find lower ex-ante welfare gains from eliminating Medicare when we account for the costs of transition. Lastly, we find that a majority of the current population benefits from the reform but that aggregate welfare, measured as the dollar value of the sum of wealth equivalent variations, is higher with Medicare.

Juan Carlos Conesa

Department of Economics

Stony Brook University

SBS Building, Office S-637

Stony Brook, NY 11794-4384

juan.conesa@stonybrook.edu

Daniela Costa

Department of Economics

University of Minnesota

1925 Fourth Street South

Minneapolis, MN 55455-0462

costa096@umn.edu

Parisa Kamali

Department of Economics

University of Minnesota

1925 Fourth Street South

Minneapolis, MN 55455-0462

jala1008@umn.edu

Timothy J. Kehoe

University of Minnesota

Department of Economics

1925 Fourth Street South

Minneapolis, MN 55455-0462

and Federal Reserve Bank of Minneapolis

and also NBER

tkehoe@umn.edu
Vegard M. Nygard

Department of Economics

University of Minnesota

1925 Fourth Street South

Minneapolis, MN 55455-0462

nygar028@umn.edu

Gajendran Raveendranathan

Department of Economics

University of Minnesota

1925 Fourth Street South

Minneapolis, MN 55455-0462

rave0049@umn.edu

Akshar Saxena

T. H. Chan School of Public Health

Harvard University

677 Huntington Avenue

Boston, MA 02115-6028

aks511@mail.harvard.edu 


\section{Introduction}

Medicare is one of the largest health insurance programs in the world. In 2015 it provided health insurance to about 52 million Americans and comprised 17.3 percent of federal outlays, or 3.6 percent of GDP. This paper aims to improve our understanding of the role of Medicare in the macroeconomy. To do this, we develop a general equilibrium overlapping generations model with incomplete markets and heterogeneous consumers. In the model, consumers differ along the dimensions of age, education, health status, labor productivity, assets, and health insurance status. The consumers are subject to idiosyncratic uncertainty on their labor productivity and health, the latter of which determines their medical expenses. While shocks to labor productivity are uninsurable, medical expenses are partially insurable in the form of Medicare, Medicaid, private, and employer-provided health insurance. We use the model to calculate the effects of an unexpected elimination of Medicare. This numerical experiment enables us to capture the effects of Medicare on macroeconomic aggregates, insurance enrollment, government spending, and welfare.

We start by comparing the steady state of the economy with and without Medicare. Eliminating Medicare leads to a 2.7 percentage point reduction in payroll taxes and a 1.3 percent increase in wages. Wages increase because capital increase as consumers raise their saving to finance the higher cost of medical expenses in old age. The combination of higher wages and lower payroll taxes raises labor supply and generates an increase in output per capita of 2.0 percent.

We then compare the insurance distribution in the two economies. Our results show that a large share of the elderly respond by substituting Medicaid for Medicare. This increases spending on Medicaid from 3.6 to 5.3 percent of GDP. Spending on Social Security benefits also increases from 4.7 to 4.8 percent of GDP because wages surge following the rise in capital. As a result, government spending as a share of GDP only declines by 1.5 percentage points following the elimination of Medicare. We thus find that the government saves only 46 cents for every dollar it cuts on Medicare due to offsetting spending on Medicaid and Social Security.

Next, we examine the ex-ante welfare effects of the reform on unborn consumers under the veil of ignorance. We find that ex-ante welfare is higher in the steady state without Medicare. In particular, we find that consumption has to increase by 3.6 percent in all periods and contingencies in the economy with Medicare to make an unborn consumer under the veil of ignorance indifferent between the two steady states. This follows from the observation that the reform leads to lower taxes and higher wages, both of which facilitate higher consumption and saving.

We then examine the ex-post welfare effects of the reform on the current cohorts. To do this, we first solve for the transition path between the economy with and without Medicare. This enables us to account for the costs of transiting between the steady states. In particular, it enables us to account for the costs of accumulating assets to finance the higher cost of medical expenses in old age.

We start by examining the ex-post welfare effects on consumers in different age brackets. Our estimates show that the majority of the young would benefit from the policy change due to the reform's effect on payroll taxes and wages. The majority of the elderly, on the other hand, are better off in the economy with Medicare. After summing across all age brackets, we find that 56.8 percent of the population alive in the period of the reform would benefit from the elimination of the program.

Next, we quantify the ex-post welfare effects on those that benefit and lose from the reform by computing the dollar value of how much wealth must change in the initial steady state to make the consumers weakly

better off in the economy with Medicare than in the transition to the economy without Medicare. We find that those that benefit from the reform experience an average welfare gain that is equivalent to receiving $\$ 3,600$ 
higher wealth in the steady state with Medicare. In contrast, those that lose from the reform experience an average welfare loss that is equivalent to at least a $\$ 27,700$ reduction in wealth. As a result, we find that the elimination of Medicare lowers aggregate welfare, and that the per capita welfare loss of the reform is equivalent to at least a $\$ 9,900$ reduction in wealth in the initial steady state. Note that this is a lower bound for the welfare loss of the reform. This follows from the fact that consumers are not allowed to borrow in our model. Consequently, some consumers will be strictly better off in the economy with Medicare even if they forfeit all of their current wealth. In this case, we find that the constraint binds for 9.4 percent of the population.

Lastly, we consider an additional ex-post welfare measure that quantifies the welfare effect by computing the average consumption equivalent variation across consumers. We show that our finding that aggregate welfare declines following the elimination of Medicare is robust to using this alternative welfare measure.

The paper is organized as follows. The next section relates our contribution to the literature. In section 3 we lay out the environment of our economy and set up a quantitative life cycle model. This section also presents the different types of health insurance that are available in the economy. After calibrating the model in section 4, we turn to the policy experiments. Section 5 starts by studying the macroeconomic effects of eliminating Medicare. The section also considers an alternative reform where we eliminate both Medicare and Medicaid. Section 6 discusses the robustness of our results to alternative parameterizations of the model. Lastly, section 7 concludes and gives directions for future research.

\section{Relation to the literature}

This paper is related to several strands of the literature. Our framework is similar to the one Conesa and Krueger (1999) use to study the aggregate effects of Social Security reforms. Their model has two essential features for our analysis. First, it takes a life cycle perspective on consumption, assets, and labor decisions. Second, it accounts for general equilibrium feedback effects. We extend their model by incorporating idiosyncratic risk to health and by allowing consumers to enroll in private and public health insurance programs.

We build on the literature that uses overlapping generations models to study the macroeconomic effects of health and aging. Attanasio et al. (2010) study the implications of an aging population for the financing of Medicare, but they do not explicitly model Medicaid, a program that we show is essential to determine consumers' saving and insurance behavior upon changes to Medicare. Pashchenko and Porapakkarm (2013) study the welfare effects of the Patient Protection and Affordable Care Act (ACA). Our model is closely related to theirs, except that we endogenize the retirement decision, since 20 percent of the population aged 65 and older are still active in the labor market. Jung and Tran (2016) use a model with endogenous health to quantify the effects of ACA. They do not, however, study transitional dynamics. Conesa and Krueger (1999) and Krueger and Ludwig (2016) argue that a full characterization of the transition path is crucial for policy evaluation. Comparative statics exercises fail to account for potentially large transitional costs, and hence give at best a partial picture of the effects of policy reforms. Bairoliya et al. (2017) and İmrohoroğlu and Zhao (2017) develop overlapping generations models to study health insurance and social security reforms in China. McGrattan and Prescott (2017) propose an overlapping generations model to study the impacts of fiscal policies in economies that are undergoing a demographic change. Lastly, Borella et al. (2017) examine the importance of including gender and marriage in structural life cycle models.

We also contribute to the literature on precautionary saving and its interaction with medical expenditure shocks. Hubbard et al. (1994) and Palumbo (1999) study the role of out-of-pocket medical expenditure risk 
in life cycle models. De Nardi et al. (2010) find that accounting for medical expense risk is important in explaining the observed saving of the elderly.

Lastly, our paper is related to the empirical literature studying social insurance programs. Finkelstein (2007) and Finkelstein and McKnight (2008) estimate the impact of Medicare on insurance coverage, health care utilization, and spending. They find that the introduction of Medicare increased the share of elderly with insurance coverage by 75 percentage points and led to a significant reduction in the elderly's exposure to out-of-pocket medical expenditure risk. Finally, Michaud et al. (2017) examine the impact of demographic changes on Social Security Disability Insurance trends.

\section{Model}

The following subsections present the benchmark model used in the analysis. The model is a discrete time, general equilibrium, overlapping generations model with ex-ante heterogeneous consumers, where consumers differ in age, educational level, health status, labor productivity, assets, and health insurance status.

\subsection{Consumers}

The economy is populated by a continuum of ex-ante consumers. Consumers are indexed by type $s=$ $(j, e, h, \eta, a, i)$, where $j$ denotes age, $e$ is educational level, $h$ denotes health status, $\eta$ is labor productivity, $a$ denotes assets, and $i$ is the consumer's health insurance status. Throughout we let $\Phi(s)$ denote the measure of consumers of type $s$.

The consumer's educational level can take on one of two values: college or non-college. For simplicity, we assume that the consumer's educational level is permanent over her lifetime. Health status is stochastic and depends on the consumer's current age, education, and health. It follows a finite-state Markov process with stationary transitions over time:

$$
Q_{j, e}(h, H)=\operatorname{Prob}\left(h^{\prime} \in H:(h, j, e)\right) .
$$

Labor productivity is given by a stationary finite-state Markov process:

$$
Q(\eta, E)=\operatorname{Prob}\left(\eta^{\prime} \in E: \eta\right)
$$

Lastly, the consumer's health insurance status specifies if she is self-insured or has private health insurance, employer-provided health insurance, or health insurance provided by the government in the form of Medicare. Health insurance is used to cover medical expenses, $m_{j h}$, which vary with the consumer's age and health status.

Consumers are endowed with one unit of time in every period that can be allocated to work and leisure. We assume that consumers can work in old age. This assumption is motivated by the observation that nearly 20 percent of individuals aged 65 and older still participate in the workforce. Labor supply, $\ell$, is indivisible and can take on one of four values: $\ell \in\left\{0, \ell_{p}, \ell_{f}, \ell_{e}\right\}$, where $p, f$, and $e$ refer to part time, full time, and extra time, respectively. In addition to leisure, consumers also derive utility from consumption, $c$. 
The period-by-period return function is given by

$$
U(c, \ell)=\frac{\left[c^{\gamma}(1-\ell)^{1-\gamma}\right]^{1-\sigma}}{1-\sigma} .
$$

Starting at age $j_{r}$, all consumers receive health insurance from the government in the form of Medicare. They also receive Social Security benefits $S S_{e}$ that depend on their education. Lastly, consumers face a survival probability $\psi_{j e h}$ that depends on their age, education, and health. All consumers that survive until age $J$ die with probability one. In the event of death, the consumer's assets are uniformly distributed across the population by means of lump-sum transfers, $B$.

\subsection{Health insurance and government welfare programs}

This section presents the different types of health insurance that are available in the economy. As noted earlier, health insurance is available in the form of private insurance, employer-provided insurance, and Medicare. Health insurance is also provided by the government in the form of Medicaid and a combination of food stamps and basic medical relief (for brevity, referred to as food stamps below). The consumer's insurance status determines what fraction of her medical expenses must be paid out-of-pocket, $m_{o p}$. Throughout, we let $\chi_{P}, \chi_{E}, \chi_{C A R E}$, and $\chi_{C A I D}$ denote the copayment parameter for private health insurance, employerprovided health insurance, Medicare, and Medicaid, respectively.

\subsubsection{Private health insurance}

Consumers can purchase health insurance for the following period from private insurance companies. We let private insurance companies price-discriminate based on age, education, and health. We assume that the price is actuarially fair for each insurance pool $(j, e, h)$. That is, the firm breaks even on each insurance pool. This gives the following expression for the insurance premium:

$$
\pi_{j e h}=\left\{\begin{array}{cc}
\frac{\psi_{j e h}\left(1-\chi_{P}\right) \int m_{j^{\prime} h^{\prime}} Q_{j, e}\left(h, d h^{\prime}\right)}{\left(1+r^{\prime}\right)} & \text { if } j<j_{r}-1 \\
\frac{\psi_{j e h}\left(1-\chi_{P}\right) \chi_{C A R E} \int m_{j^{\prime} h^{\prime}} Q_{j, e}\left(h, d h^{\prime}\right)}{\left(1+r^{\prime}\right)} & \text { if } j \geq j_{r}-1 .
\end{array}\right.
$$

We assume that Medicare is the primary payer for all elderly consumers. That is, in the event that a consumer is covered by both Medicare and private insurance, Medicare pays first.

\subsubsection{Employer-provided health insurance}

We assume that a fraction of workers have health insurance provided by their employer. The employer pools the medical expenses of all their employees that do not choose to go on food stamps. These costs are then split evenly between all employees that currently work positive hours. That is, we model employer-provided health insurance as a pay-as-you-go system where current contributors pay for the health expenditures of current receivers. The premium is thus given by

$$
\bar{\pi}_{E}=\frac{\left(1-\chi_{E}\right) \int \mathbb{I}_{F=0} m_{j h} \Phi\left(\left\{1, \ldots, j_{r}-1\right\} \times d e \times d h \times d \eta \times d a \times\left\{i^{E}\right\}\right)}{\int \mathbb{I}_{\ell>0} \Phi\left(\left\{1, \ldots, j_{r}-1\right\} \times d e \times d h \times d \eta \times d a \times\left\{i^{E}\right\}\right)},
$$


where the indicator function $\mathbb{I}_{F=0}$ in the numerator equals one for all consumers that do not choose to go on food stamps. We assume that consumers cannot have both employer-provided and private health insurance, and that consumers cannot opt out of employer-provided insurance. The latter assumption is needed to alleviate the adverse selection problem associated with group insurance plans, which would arise in our model due to our abstracting from tax deductions for employer-provided health insurance premia. Jeske and Kitao (2009) find that these deductions discourage healthy individuals to opt out of group insurance in favor of private insurance. Lastly, we assume that consumers aged $j_{r}$ and older are not eligible for employerprovided health insurance. This is motivated by data from the Medical Expenditure Panel Survey which show that the percentage of individuals with employer-provided insurance drops from about 50 to 20 percent between the ages of 60 and 70. Since consumers aged $j_{r}$ and older are not eligible for employer-provided health insurance, we let consumers of age $j_{r}-1$ with employer-provided insurance purchase private insurance for the following period.

\subsubsection{Medicaid}

Medicaid is a means-tested program that provides health insurance to the poor. There are two ways to qualify for Medicaid. First, consumers are eligible for Medicaid if the sum of their gross income and interest earnings is below a threshold $y^{\text {cat }}$. Second, consumers also qualify for Medicaid if the sum of their gross income and interest earnings net of out-of-pocket medical expenses is below a threshold $y^{m n}$ and their assets are less than $a^{m n}$. Following Pashchenko and Porapakkarm (2013), we call the two eligibility criteria "categorical eligibility" and "eligibility based on medical need," respectively.

\subsubsection{Medicare}

The government also provides health insurance in the form of Medicare. Unlike Medicaid, Medicare is not a means-tested program, but provides equal health insurance to all the elderly. Since Medicare does not cover all out-of-pocket medical expenses, elderly consumers can purchase private insurance as a complementary insurance.

\subsubsection{Food stamps and basic medical relief}

Finally, the government provides health insurance in the form of a combined food stamps and basic medical relief program. The program combines institutional features of food stamps, disability insurance, and basic medical relief for the poor. To qualify for this program in the model, consumers have to forfeit all assets and work zero hours. In return, the government pays for all out-of-pocket medical expenses and guarantees a minimum consumption level, $\underline{\text { c. }}$

\subsection{Consumer problem}

The consumer's choice set depends on her current age and insurance status. Throughout, we use the word young to denote consumers less than age $j_{r}$ and old to denote consumers that are at least $j_{r}$ years old. We start by presenting the problem of a young consumer without employer-provided health insurance. This subsection also defines the value of going on food stamps. Next, we set up the problem faced by young consumers with employer-provided health insurance. Lastly, we discuss the problem of old consumers. 


\subsubsection{Young consumers without employer-provided health insurance}

Recall that a consumer's type is given by $s=(j, e, h, \eta, a, i)$, where $j$ denotes age, $e$ is educational level, $h$ denotes health status, $\eta$ is labor productivity, $a$ denotes assets, and $i$ is the consumer's health insurance status. Let $V^{I}(s)$ denote the value of young consumers without employer-provided health insurance. Similarly, let $V^{F}(s)$ denote the value of food stamps. Consumers without employer insurance that do not choose to go on food stamps may or may not purchase private insurance for the following period. This yields the following problem:

$$
V(s)=\max \left\{V^{I}(s), V^{F}(s)\right\},
$$

where $V^{I}(s)$ is given by

$$
\begin{aligned}
& V^{I}(s)=\max _{c, a^{\prime}, \ell, i^{\prime}} U(c, \ell)+\beta \psi_{j e h} \iint V\left(s^{\prime}\right) Q\left(\eta, d \eta^{\prime}\right) Q_{j, e}\left(h, d h^{\prime}\right) \\
& \text { s.t. } \quad c+a^{\prime}+m_{o p}+\mathbb{I}_{i^{\prime}=i_{P}} \pi_{j e h}=w(1-\tau) \epsilon_{j e} \eta \xi(h) \ell \\
& +(1+r)(a+B)+\mathbb{I}_{M e d}(s, \ell)\left(1-\chi_{C A I D}\right) m_{o p} \\
& m_{o p}=\mathbb{I}_{i=i_{P}} \chi_{P} m_{j h}+\left(1-\mathbb{I}_{i=i_{P}}\right) m_{j h} \\
& \ell \in\left\{0, \ell_{p}, \ell_{f}, \ell_{e}\right\} \\
& c, a^{\prime} \geq 0 \\
& i^{\prime} \in\left\{i_{P}, i_{S}\right\} \text {. }
\end{aligned}
$$

Here, $i=i_{P}$ means the consumer has private health insurance, and $i=i_{S}$ means the consumer is self-insured. The indicator function, $\mathbb{I}_{M e d}(s, \ell)$, equals one if the consumer qualifies for Medicaid. Medicaid covers a share $1-\chi_{C A I D}$ of out-of-pocket medical expenses, which are given by $m_{j h}$ for self-insured consumers and $\chi_{P} m_{j h}$ for consumers that purchased private insurance in the preceding period. Lastly, labor earnings depend on the consumer's stochastic labor productivity, $\eta$, health, $\xi(h)$, and deterministic life cycle productivity, $\epsilon_{j e}$, the last of which varies with age and education.

To qualify for food stamps in the model, consumers have to forfeit all assets and work zero hours. In return, the government covers all out-of-pocket medical expenses and provides the consumer with consumption c. The value of food stamps is thus given by

$$
\begin{array}{ll}
V^{F}(s)= & U(\underline{\mathrm{c}}, 0)+\beta \psi_{j e h} \iint V\left(s^{\prime}\right) Q\left(\eta, d \eta^{\prime}\right) Q_{j, e}\left(h, d h^{\prime}\right) \\
\text { s.t. } \quad & a^{\prime}=0 \\
& i^{\prime}=i_{S} .
\end{array}
$$

\subsubsection{Young consumers with employer-provided health insurance}

Let $V^{E}(s)$ denote the value of being on employer-provided health insurance. Consumers with employer insurance choose whether or not to go on food stamps. This yields the following problem:

$$
V(s)=\max \left\{V^{E}(s), V^{F}(s)\right\}
$$


where $V^{E}(s)$ is given by

$$
\begin{aligned}
& V^{E}(s)=\quad \max _{c, a^{\prime}, \ell} U(c, \ell)+\beta \psi_{j e h} \iint V\left(s^{\prime}\right) Q\left(\eta, d \eta^{\prime}\right) Q_{j, e}\left(h, d h^{\prime}\right) \\
& \text { s.t. } \quad \begin{array}{r}
c+a^{\prime}+m_{o p}+\mathbb{I}_{\ell>0} \bar{\pi}_{E}=w(1-\tau) \epsilon_{j e} \eta \xi(h) \ell \\
+(1+r)(a+B)+\mathbb{I}_{M e d}(s, \ell)\left(1-\chi_{C A I D}\right) m_{o p}
\end{array} \\
& \\
& \quad m_{o p}=\chi_{E} m_{j h} \\
& \qquad \begin{array}{ll}
\ell \in \begin{cases}0, \ell_{p}, \ell_{f}, \ell_{e} & \text { if sick } \\
\ell_{p}, \ell_{f}, \ell_{e} & \text { if healthy }\end{cases} \\
\\
c, a^{\prime} \geq 0 \\
i^{\prime}=i_{E} .
\end{array}
\end{aligned}
$$

Out-of-pocket medical expenses are given by $\chi_{E} m_{j h}$ for consumers on employer insurance. All consumers on employer insurance that work positive hours must pay a premium $\bar{\pi}_{E}$. We assume that healthy consumers on employer insurance have to supply a minimum of $\ell_{p}>0$ hours. Sick consumers, on the other hand, are free to choose zero hours. In the model, consumers are considered sick if they have a catastrophic health state. Finally, the value of going on food stamps is the same as above, with the exception that consumers continue to be eligible for employer-provided insurance in the following period, $i^{\prime}=i_{E}$.

\subsubsection{Old consumers}

Let $V^{R}(s)$ denote the value of an old consumer of type $s$. Similarly to young consumers without employerprovided health insurance, old consumers that do not choose to go on food stamps may or may not purchase private insurance for the following period. This yields the following problem:

$$
V(s)=\max \left\{V^{R}(s), V^{F}(s)\right\}
$$

where $V^{R}(s)$ is given by

$$
\begin{aligned}
& V^{R}(s)= \max _{c, a^{\prime}, \ell, i^{\prime}} U(c, \ell)+\beta \psi_{j e h} \iint V\left(s^{\prime}\right) Q\left(\eta, d \eta^{\prime}\right) Q_{j, e}\left(h, d h^{\prime}\right) \\
& \text { s.t. } \quad \begin{array}{c}
c+a^{\prime}+m_{o p}+\mathbb{I}_{i^{\prime}=i_{P}} \pi_{j e h}=w(1-\tau) \epsilon_{j e} \eta \xi(h) \ell \\
\quad+(1+r)(a+B)+S S_{e}+\mathbb{I}_{M e d}(s, \ell)\left(1-\chi_{C A I D}\right) m_{o p}
\end{array} \\
& \\
& \quad m_{o p}=\mathbb{I}_{i=i_{P}} \chi_{P} \chi_{C A R E} m_{j h}+\left(1-\mathbb{I}_{i=i_{P}}\right) \chi_{C A R E} m_{j h} \\
& \ell \in\left\{0, \ell_{p}, \ell_{f}, \ell_{e}\right\} \\
& c, a^{\prime} \geq 0 \\
& i^{\prime} \in\left\{i_{P}, i_{S}\right\} .
\end{aligned}
$$


All consumers start receiving Medicare and Social Security benefits at age $j r$. Neither program is tied to retirement, and hence consumers continue to receive both Medicare and Social Security benefits even if they choose to work in old age. Out-of-pocket medical expenses are given by $\chi_{C A R E} m_{j h}$ for self-insured consumers and $\chi_{C A R E} \chi_{P} m_{j h}$ for consumers that purchased private insurance in the preceding period.

\subsection{Firms}

Firms hire labor at wage $w$ and rent capital at rate $r$ from the consumers to maximize profits. We assume that the aggregate technology can be represented by a constant returns to scale Cobb-Douglas production function:

$$
Y=\theta K^{\alpha} N^{1-\alpha}
$$

where $\theta$ denotes total factor productivity, $K$ is the aggregate capital stock, $N$ denotes aggregate labor supply (measured in efficiency units), and $\alpha$ is capital's share of income. Output is used for consumption, $C$, investment, $I=K^{\prime}-(1-\delta) K$, and to cover medical expenses, $M$ :

$$
C+M+K^{\prime}=\theta K^{\alpha} N^{1-\alpha}+(1-\delta) K
$$

where $\delta$ is the rate of depreciation.

\subsection{Government}

Let $b_{e}$ denote the Social Security replacement rate conditional on the consumer's educational level. Social Security benefits $S S_{e}$ then satisfy

$$
S S_{e}=\frac{b_{e} w N}{\int \Phi\left(\left\{1, \ldots, j_{r}-1\right\} \times d e \times d h \times d \eta \times d a \times d i\right)} .
$$

The government finances its costs of providing health insurance, food stamps, and Social Security by means of payroll taxes. For simplicity, we assume that the government balances its budget period-by-period. Let gov denote the total government expenditure on health insurance and food stamps. Taxes on labor income, $\tau$, then have to satisfy

$$
\tau w N=S S_{e} \int \Phi\left(\left\{j_{r}, \ldots, J\right\} \times d e \times d h \times d \eta \times d a \times d i\right)+\text { gov } .
$$

\subsection{Definition of equilibrium}

Given a replacement rate $b_{e}$, copayment parameters $\chi_{P}, \chi_{E}, \chi_{C A R E}$, and $\chi_{C A I D}$, and initial conditions for capital $K_{1}$ and the measure of types $\Phi_{1}$, an equilibrium in our model is a sequence of model variables such that:

1. Given prices, insurance premia, government policies, and accidental bequests, consumers maximize utility subject to their constraints.

2. Factor prices satisfy marginal product pricing conditions.

3. Government policies satisfy the government budget constraint.

4. Goods, factor, and insurance market clearing conditions are met. 
5. Aggregate law of motion for $\Phi$ is induced by the policy functions and the exogenous stochastic processes for idiosyncratic risk.

\section{Calibration}

This section describes how we map the model to the data. We start by presenting the health expenditure data used in this paper. Next, we discuss how we compute the health insurance copayment parameters, how the Medicaid eligibility criteria are determined, and how we compute the health transition probabilities. The last two subsections summarize the calibration of the preference and technology parameters, and the parameters of the idiosyncratic earnings process.

\subsection{Health expenditure}

We use data from the Medical Expenditure Panel Survey (MEPS). The MEPS collects detailed records on medical expenditure, insurance, income, and demographics for a nationally representative sample of households. The survey consists of two-year overlapping panels for the period 1996 to 2013, of which we use data from 1996 to 2010 for individuals aged 20 to 85 years. All current price series are converted to 2010 dollars using the GDP deflator.

We split medical expenses into three categories: low, high, and catastrophic. To identify these expenses in the data, we first pool all medical expenses for each age group and compute the 60th and 99.9th percentile. We then identify low, high, and catastrophic expenses as the average value between the $0-60$ th percentile, the 60-99.9th percentile, and the 99.9-100th percentile. Next, we assume a logarithmic trend. Since the MEPS pools all medical expenses for individuals older than 85 , we extrapolate medical expenses for consumers aged 85 to 100. Lastly, we scale the expenditures to match the 16.5 percent health expenditures-to-GDP ratio observed in the United States between 2006 and 2010. These series are illustrated in figure 1. We also report how medical expense risk varies over the life cycle. This is illustrated in figure 2, which shows that both the mean and variance of medical expenses increase as people age.

\subsection{Health insurance parameters and Medicaid eligibility criteria}

To compute the copayment parameter on private insurance, employer insurance, and Medicaid, we first derive each consumer's primary insurance provider, defined as the insurer that pays for most of the consumer's expenses. For instance, if Medicaid covers most of the consumer's expenses, but she also pays some expenses out-of-pocket, Medicaid will be her primary insurance provider. We then compute the average share of expenses paid by Medicaid across consumers with Medicaid as their primary insurance provider, and let the copayment parameter on Medicaid be given by the complement of this share. The same method is used to compute the copayment parameter on private insurance and employer insurance. Given data from the MEPS, we obtain a copayment parameter on private insurance and employer insurance of 22.9 percent, and a copayment parameter on Medicaid of 13.8 percent. We use the same copayment parameter on private and employer insurance since the MEPS pools expenses covered by these insurance plans.

Recall that all of the elderly receive Medicare in the model and that Medicare is their primary payer (that is, in the event that an old consumer is covered by multiple insurance plans, Medicare pays first). An implication of this assumption is that the percentage of the elderly's total health expenses that is paid by Medicare will always be equal to the complement of the Medicare copayment parameter in the model. In 
other words, using a Medicare copayment parameter of $x$ percent means that Medicare will pay for $1-x$ percent of the elderly's total medical expenses. Data from the MEPS show that Medicare pays for 46.9 percent of the elderly's total health expenses and for 70.9 percent of the medical expenses of those with Medicare as their primary insurance provider. To better match the age-specific insurance distribution in the data, we pick a value closer to the first estimate and let the copayment parameter on Medicare be 50.0 percent.

Prior to ACA, financial eligibility criteria for Medicaid varied considerably across states, but were typically well below the federal poverty level (FPL). Data from the Kaiser Family Foundation show that 33 states had a categorical income limit below the FPL in 2009 , which was about $\$ 10,800$, or 23 percent of GDP per capita. The weighted average categorical income limit, with weights given by each state's share of total health expenses, was 90.2 percent of the FPL. The categorical income limit in the model is set to match this 90.2 percent weighted average limit. Next, among the 34 states that had a Medicaid medically needy program in 2009, 30 states had a medically needy income limit below the FPL, and 23 states had a medically needy asset limit below $\$ 2,500$. The corresponding weighted average medically needy income and asset thresholds across the states with a medically needy program were 41.9 percent of the FPL and $\$ 1,950$, respectively. We set the medically needy income and asset thresholds to match these weighted average limits. A summary of the health insurance parameters is given in table 1.

\subsection{Health transition and death probabilities}

The health transition matrix must guarantee that, for each age and educational level, 60, 39.9, and 0.1 percent of consumers have low, high, and catastrophic medical expenses, respectively. Similarly, the survival probabilities must ensure that the age, health, and education specific survival probabilities are consistent with what we observe in the data. The following discussion explains how we adjust the health transition matrix to ensure consistency with the data. Using our MEPS sample, we first estimate age, health, and education specific health transition and death probabilities by running an ordered probit regression of next period's health on current age, age squared, education, health, and interaction terms. Next, we scale the probabilities to match the age-specific death probabilities reported by the Social Security Administration. This last step is necessary since individuals drop out of the MEPS when they become institutionalized, which biases the death probability estimates from the MEPS. Lastly, we iterate on the transition matrix by means of the RAS-method until the probabilities guarantee that, for each age and educational level, the correct percentage of consumers transition to each health state.

\subsection{Preference, technology, and life cycle parameters}

Consumers enter the model at age 20. We set $j_{r}$ to 47 so that consumers start receiving Medicare and Social Security benefits at age 66 . The maximum life span is set to 100 years. We follow Conesa and Krueger (1999) and set the population growth rate to 1.1 percent per year. Together with the estimated survival probabilities, these values give an old age dependency ratio (that is, the ratio of population older than 65 over population between 20 and 65 ) of 22.3 percent, slightly more than the 20.9 percent reported by the 2009 U.S. Census. Capital's share of income is set to 0.36. We follow Castañeda et al. (2003) and set the depreciation rate to 0.059 . We set the consumption share in intratemporal utility to 0.574 to match estimates in French (2005), and set $\sigma$ to 2.742 to match an intertemporal elasticity of substitution (IES) of 0.5. Next, consumers are endowed with one unit of time in every period that can be allocated to work and leisure. We set the 
grid for labor supply to $\ell \in\{0,0.225,0.300,0.375\}$, which corresponds to working zero hours, part time, full time, and overtime, respectively. We let $\xi(h)$ be equal to 1 for agents with low and high health expenditures, and 0 for agents with catastrophic expenses. Given data from the MEPS, we estimate deterministic labor productivity profiles, $\epsilon_{j e}$, by regressing the logarithm of wages on age, education, higher-order moments of age, and interaction terms. Lastly, we set the fraction of consumers with at least a four-year college degree to 23.5 percent and let the remaining share be denoted as consumers without a college degree to match estimates in the MEPS. A summary of the non-insurance parameters that are determined outside the model is given in table 2 .

The final set of parameters is determined jointly in equilibrium, a summary of which is given in table 3 . We calibrate $\theta$ to generate a steady state GDP per capita of 1 in the benchmark economy. The discount factor is set to 0.927 to match a capital-to-output ratio of 3 . The low value of the discount factor is attributed to consumers being subject to idiosyncratic shocks to both labor productivity and health expenditures. Consumers accordingly save more in our model than in standard life cycle models where consumers only face shocks to labor productivity. A lower value of $\beta$ is thus needed to generate the desired capital-tooutput ratio. The Social Security replacement rates are calibrated to match average Social Security benefits across individuals with and without a college degree. The assumption that benefits depend on education is motivated by the fact that Social Security benefits are tied to lifetime earnings in the United States, which is correlated with educational attainment. Next, we set the consumption floor, $\underline{\mathrm{c}}$, to match the average annual Supplemental Nutrition Assistance Program benefits reported by the United States Department of Agriculture. Lastly, we calibrate the mass of 20-year-olds that qualify for employer-provided insurance to match the mass of individuals with either private or employer insurance in the data.

\subsection{Earnings process}

We follow Castañeda et al. (2003) and calibrate the parameters of the labor earnings process to match the empirical earnings distribution in the United States. We choose a right-skewed productivity shock process to match the top decile of the earnings distribution, and calibrate the variance of the process to match the dispersion observed in the data. The comparison of the labor earnings distribution in the model and the data reported in table 4 shows that the model successfully matches the empirical distribution. A similar comparison of the wealth distribution is given in table 5. Although we do not calibrate the model to match this distribution, the table verifies that the model generates a concentration and right skewness of wealth that is comparable to what we observe in the data.

\section{Results}

We use the model to run two policy experiments. We start by studying the macroeconomic effects of eliminating Medicare from the benchmark economy. We then analyze an alternative reform where we eliminate both Medicare and Medicaid.

Before we present the policy experiments, we first evaluate the performance of the model by comparing the distribution of medical expenses by age and provider in the model and the data. Figure 3 shows that the benchmark model captures several features of the age-specific insurance distribution in the MEPS. The model is consistent with the fact that medical expenses in young age are largely paid out-of-pocket, by Medicaid, and by private and employer-provided insurance plans, and that the majority of expenses in old age are covered by Medicare. Quantitatively, the model also largely matches the percentage of expenses covered by Medicare, 
private, and employer-provided insurance plans over the life cycle. The model underestimates the expenses paid out-of-pocket and overestimates the expenses covered by Medicaid. The latter discrepancy between the model and the data is partly driven by the Medicaid income tests. Recall that we set the categorical and medically needy income thresholds to match the 90.2 and 41.9 percent weighted average limits in the data, respectively. The corresponding median categorical and medically needy income thresholds are 64.0 and 50.5 percent. Using the median rather than weighted mean income limits in the model lowers the percentage of expenses covered by Medicaid for the young and increases the corresponding share for the old. We choose the weighted mean estimates to better match the insurance distribution of the elderly. A sensitivity analysis reported in section 6 shows that our results are robust to using median income and asset tests. With easier access to Medicaid, however, a larger share of the elderly is able to substitute into Medicaid. As a result, the saving to the government from eliminating Medicare is only 44 cents on the dollar in the model with median income and asset limits, in contrast to 46 cents on the dollar with weighted average limits. Lastly, figure 3 shows that other insurance programs cover about 7 percent of health expenses of all age groups in the data. In the model, this insurance plan corresponds to our combined food stamps and basic medical relief program. We find that the share of health expenses paid by this program declines with age and approaches zero for the elderly, a result that follows directly from the assumption that consumers have to forfeit all assets and work zero hours to qualify for the program.

\subsection{Eliminating Medicare}

Our first policy experiment involves an unexpected elimination of Medicare. Starting from the benchmark economy, we lower the insurance coverage rate of Medicare to zero and study the macroeconomic effects as the economy transitions to a new steady state without Medicare. By "macroeconomic effects," we mean the effects of the policy reform on consumption, assets, output, insurance choice, government spending, and welfare. We study not only comparative statics but also the full transition path between the economies, which Conesa and Krueger (1999) and Krueger and Ludwig (2016) have shown to be crucial for evaluating Social Security and education policy reforms.

\subsubsection{Macroeconomic aggregates, insurance enrollment, and government spending}

Table 6 compares the steady state of the economy with and without Medicare. Eliminating Medicare leads to a 2.7 percentage point reduction in payroll taxes and a 1.3 percent increase in wages. The increase in wages follows from the 4.4 percent increase in capital per capita. Capital increases as consumers raise their saving to finance the higher cost of medical expenses in old age. The combination of higher wages and lower payroll taxes raises labor supply and generates an increase in output per capita of 2.0 percent.

Table 7 reports the insurance distributions in the two steady states. As consumers are allowed to combine health insurance policies (for instance, an old consumer on Medicare can purchase private insurance), we define a consumer's main insurance provider as the insurance plan that pays for the largest share of her medical expenses. For instance, a consumer is defined to be on employer-provided health insurance if most of her medical expenses are paid by the employer. The table also reports the percentage of total medical expenses covered by each insurance plan. Note that total health expenses are equal in the two economies since all medical spending is non-discretionary in the model. In the benchmark economy, 18.2 percent of consumers have Medicare as their primary health insurance provider. Not surprisingly, eliminating Medicare increases the percentage of self-insured consumers and the fraction of consumers with private insurance as 
their main provider. More interestingly, we find that the policy reform raises the percentage of consumers with Medicaid as their primary health insurance provider from 16.4 to 20.8 percent. As Medicaid coverage increases, total medical expenses covered by Medicaid also rises from 22.1 to 32.3 percent.

Figure 4, which plots Medicaid enrollment by age in the economy with and without Medicare, shows that all of the increase in the Medicaid coverage rate is driven by the elderly, who respond to the removal of Medicare by partially substituting Medicaid for Medicare. To better understand how Medicare affects Medicaid enrollment, we compute the percentage of people in each age bracket that qualify for Medicaid under the categorical and medically needy criterion in the two economies. Recall that consumers qualify for Medicaid under the categorical criterion if the sum of their gross income and interest earnings is below the categorical threshold. Similarly, consumers qualify for Medicaid under the medically needy criterion if the sum of their gross income and interest earnings net of out-of-pocket medical expenses and their assets are both below the corresponding limits. Given our calibration of the categorical income limit and Social Security replacement rates, none of the elderly qualify for Medicaid under the categorical criterion in the two economies. All of the increase in the Medicaid coverage rate is thus driven by an increase in the percentage of elderly that qualifies under the medically needy criterion because the reform lowers the elderly's net income. Note that net income declines even though the elderly respond to the reform by increasing their labor supply, saving, and purchase of private health insurance.

Medicare spending accounts for 3.3 percent of GDP in the benchmark economy, about $\$ 489$ billion. How much the government saves by eliminating the program depends on what happens to spending on other social insurance programs such as Medicaid, food stamps, and Social Security. Table 8 decomposes fiscal spending on these programs in the economy with and without Medicare. Eliminating Medicare leads to a rise in Medicaid expenses from $\$ 545$ to $\$ 796$ billion as the share of old consumers that qualify for the program increases. It also raises the fraction of elderly that goes on food stamps, but total spending on the program remains constant at $\$ 94$ billion since fewer young consumers go on food stamps in the economy without Medicare. Lastly, government spending on Social Security benefits increases from $\$ 699$ to $\$ 714$ billion as wages surge following the rise in capital. These estimates show that government spending on other social insurance programs increases by $\$ 266$ billion following the reform. As a result, we find that the elimination of Medicare leads to a $\$ 223$ billion annual reduction in fiscal spending. Accordingly, although Medicare spending accounts for 3.3 percent of GDP in the benchmark economy, the reform only results in a 1.5 percentage point reduction in government spending in the long run.

The $\$ 223$ billion annual reduction in fiscal spending following the $\$ 489$ billion cut in Medicare spending shows that the government saves only 46 cents for every dollar it cuts on Medicare expenses. Our results also show that most of the loss in saving following the reform can be attributed to spending on Medicaid. Put together, these findings suggest that for every dollar the government cuts on Medicare, spending on Medicaid increases by 51 cents. Consequently, eliminating Medicare will have only limited long-run fiscal effects if the current Medicaid eligibility criteria are maintained.

Recall that total health expenses are equal in the two economies and that the $\$ 489$ billion cut in Medicare expenses leads to an increase in Medicaid spending by $\$ 251$. The remaining $\$ 238$ billion increase in health spending can be attributed to private insurance, self-insurance, employer insurance, and food stamps. We find that the elderly partially respond to the reform by purchasing private health insurance, which in turn increases spending by private insurance from $\$ 296$ to $\$ 388$ billion. Similarly, the increase in the percentage of self-insured consumers leads to a surge in out-of-pocket medical spending from $\$ 565$ to $\$ 706$. Lastly, spending by employer insurance increases from $\$ 472$ to $\$ 476$ billion, and spending by food stamps increases 
from $\$ 100$ to $\$ 101$ billion. Note that total health expenses covered by food stamps exceed total government spending on food stamps since consumers have to forfeit all assets to qualify for the program.

We next examine the transition path between the economy with and without Medicare. We choose a transition duration of 100 years to ensure that the economy has sufficient time to transition to the new steady state. Starting from an initial steady state with Medicare, figure 5 shows how capital, output, consumption, and effective labor supply evolve during the first 50 years following the elimination of the program. Although the comparative statics exercise in table 6 showed that consumption per capita is 1.8 percent higher in the steady state without Medicare, the transition path shows that consumption initially drops by about 0.7 percent. In fact, the percentage change in consumption compared to the initial steady state remains negative for several years following the elimination of Medicare. Consumption declines during the transition as consumers accumulate assets to finance the higher cost of medical expenses in old age. As we have shown earlier, the surge in capital leads to higher wages and labor supply, both of which enable the consumers to save and consume more in the long run.

\subsubsection{Welfare}

This section quantifies the ex-ante and ex-post welfare effects of the reform. While the ex-ante measure refers to the effect on an unborn consumer under the veil of ignorance, the ex-post measure refers to the effect on the current cohorts.

Ex-ante welfare We quantify the ex-ante welfare effect by means of consumption equivalent variation. That is, we measure how much a consumer's consumption must increase in all periods and contingencies in the economy with Medicare to make her indifferent between the economy with and without Medicare. Let $V^{M}(s)$ denote the value of a consumer of type $s$ in the steady state with Medicare. Similarly, let $V_{t}^{N}(s)$ denote the value of a consumer of type $s$ that enters the economy in period $t$ of the transition. Finally, let $\Phi_{0}(s)=\Phi(1, e, h, \eta, 0, i)$ denote the mass of newborns of type $s$. Given our functional form for utility, we obtain the following expression for the ex-ante welfare effect on an unborn consumer under the veil of ignorance that enters the economy in period $t$ of the transition:

$$
C E V_{t}^{T r}=\left[\frac{\int V_{t}^{N}(s) \Phi_{0}(d s)}{\int V^{M}(s) \Phi_{0}(d s)}\right]^{\frac{1}{\gamma(1-\sigma)}} .
$$

Figure 6 shows how ex-ante welfare evolves during the first 50 years of the transition. That is, it shows how much consumption must increase in all periods and contingencies in the economy with Medicare to make an unborn consumer under the veil of ignorance that enters the economy in period $t$ of the transition indifferent between the benchmark economy and the transition. We find that ex-ante welfare increases by 2.1 percent for a consumer that enters in the first period of the reform. This welfare gain further increases over the transition. Consequently, we find that ex-ante welfare increases by 3.6 percent in the long run. Ex-ante welfare is higher without Medicare because payroll taxes are lower and wages are higher in the economy without Medicare, both of which facilitate higher consumption and saving.

Ex-post welfare For unborn cohorts, we do not need to compare utility across different consumers. Once a consumer is born, however, she begins as either college educated or non-college educated, and either has or does not have employer-provided health insurance. As life progresses, the consumer experiences a sequence of shocks to her health status and labor productivity. Furthermore, at any point in time there are consumers 
of different ages. Consequently, if we want to calculate some sort of aggregate ex-post welfare measure of the impact of eliminating Medicare, we have to compare gains and losses across very different consumers.

We use three alternative measures to quantify the ex-post welfare effect on the current cohorts. None of them are perfect, and we discuss the advantages and disadvantages of each measure. Our first measure avoids the problem of comparing gains and losses across different consumers by simply computing the mass of people that benefit from the reform. This measure tells us whether or not the reform would win on a vote among all consumers aged 20 and older in the period that the reform is implemented.

For our second measure, we compute the dollar value of how much wealth must change in the initial steady state to make the consumer weakly better off in the economy with Medicare than in the transition. Given that consumers are not allowed to borrow, there exists a lower bound for this change in wealth. For instance, consider a consumer that is better off in the economy with Medicare. Since wealth must be non-negative, there might not exist a sufficiently large reduction in wealth that would make this consumer indifferent between the economy with and without Medicare. For each type $s$, we therefore compute the minimum change in wealth, $W E V^{1}(s)$, that satisfies the following constraints:

$$
\begin{array}{ll}
\min & W E V^{1}(s) \\
\text { s.t. } & V^{M}\left(j, e, h, \eta, a+W E V^{1}(s), i\right) \geq V_{1}^{N}(j, e, h, \eta, a, i) \\
& a+B+W E V^{1}(s) \geq 0 .
\end{array}
$$

We then compute the average welfare effect of the reform by integrating across consumers:

$$
W E V^{1}=\int W E V^{1}(s) \Phi(d s) .
$$

Finally, for our third measure, we follow Chatterjee et al. (2007) and quantify the ex-post welfare effects by computing the average consumption equivalent variation across consumers. To do this, we first compute the percentage change in consumption in all periods and contingencies that is needed to make a consumer of type $s$ indifferent between the two economies:

$$
C E V(s)=\left[\frac{V_{1}^{N}(s)}{V^{M}(s)}\right]^{\frac{1}{\gamma(1-\sigma)}},
$$

where $V^{M}(s)$ and $V_{1}^{N}(s)$ denote the value of a consumer of type $s$ in the steady state with Medicare and in the first period of the transition, respectively. We then compute the average welfare effect of the reform by integrating across consumers:

$$
\overline{C E V}=\int C E V(s) \Phi(d s) .
$$

Unlike the second measure, this measure does not control for consumers' different levels of initial consumption, different assets, or different length of their remaining lifetime.

We start by examining how support for the policy varies with age. This is illustrated in figure 7 , which plots the percentage of consumers in different age brackets that would vote in favor of eliminating Medicare. Our result shows that the majority of young consumers are better off without Medicare. In particular, we find that the percentage of votes by age in favor of eliminating the program exceeds 50 percent for all ages up to the age of 48. This result is due to the wage and tax effect discussed earlier. Although it takes time to transition to the new steady state, these consumers are still young enough to reap most of the benefits associated with higher labor earnings. The majority of older consumers, on the other hand, are better off 
with Medicare. Note, however, that the percentage of votes by age in favor of eliminating the program does not decline monotonically with age. We find that the percentage of consumers that are better off without Medicare increases late in life. This is driven by the interplay between Medicare and Medicaid highlighted earlier. That is, more old consumers qualify for Medicaid in the economy without Medicare, which in turn lowers their cost of going through the transition. After summing across votes, we find that 56.8 percent of the population alive in the period of the reform is better off without Medicare. That is, the majority of the population would vote in favor of eliminating the program.

Next, we turn to our second welfare measure, which quantifies the ex-post welfare effect by computing the dollar value of how much wealth must change in the initial steady state to make the consumer weakly better off in the economy with Medicare than in the transition. We then compute the average change in welfare across the population that would benefit and lose from the elimination of Medicare by summing across consumers in the two groups. Our estimate shows that the winners experience an average welfare gain that is equivalent to receiving $\$ 3,600$ higher wealth in the steady state with Medicare. In contrast, the losers experience an average welfare loss that is equivalent to at least a $\$ 27,700$ reduction in wealth. The average welfare gain across the 56.8 percent of the population that would benefit from the elimination of Medicare is thus considerably lower than the average welfare loss experienced by the remaining population. As a result, we find that the elimination of Medicare lowers aggregate welfare, and that the per capita welfare loss of the reform is equivalent to at least a $\$ 9,900$ reduction in wealth in the initial steady state. Recall that this measure binds for some consumers. That is, some consumers will be strictly better off in the economy with Medicare even if they forfeit all of their current wealth. In this case, we find that the constraint binds for 9.4 percent of the population.

Finally, in terms of consumption equivalent variation, we find that the winners experience an average welfare gain that is equivalent to receiving 1.9 percent higher consumption in all periods and contingencies in the initial steady state, and that the losers experience an average welfare loss of 7.0 percent. When we average the percentage gains and losses across all consumer types, we find that the average change in the different consumption equivalent variations is a decline of 2.0 percent.

Our discussion so far has shown that the majority of the population alive in the period of the reform is better off without Medicare. Yet, aggregate welfare is higher in the benchmark economy since the welfare gain experienced by those that benefit from the reform is outweighed by the welfare loss experienced by the rest of the population. The remaining part of this section studies how these heterogeneous welfare effects vary across consumers in different health and educational states, and across consumers with different wealth and labor earnings, a summary of which is given in table 9 .

We find that the majority of college and non-college educated consumers are better off without Medicare, but that both groups experience a reduction in average welfare following the elimination of the program. Next, our results show that $56.3,57.5$, and 61.8 percent of consumers with low, high, and catastrophic medical expenses, respectively, are better off without Medicare. This follows from the fact that the majority of young consumers in all three health states benefit from the reform, which can be confirmed by examining the ageand health-specific voting outcomes reported in figure 8. Although the majority of consumers in all three health states benefit from the reform, their average welfare nevertheless declines. In particular, we find that consumers with low, high, and catastrophic medical expenses, respectively, experience an average welfare loss that is equivalent to receiving at least $\$ 10,300, \$ 9,400$, and $\$ 1,400$ lower wealth in the steady state with Medicare. The finding that welfare declines by less for consumers in catastrophic health, which also holds under our third welfare measure, is driven by the fact that most of these consumers are covered by food 
stamps or Medicaid. As shown in table 10, 72.1 percent of consumers with catastrophic medical expenses are enrolled in food stamps or Medicaid in the steady state with Medicare. This lowers the insurance value provided by Medicare to these consumers, which in turn lowers their welfare loss from the reform.

Lastly, we examine how welfare varies with wealth and labor earnings. Whereas the majority of consumers in the first four wealth quintiles are better off without Medicare, only 14.2 percent of consumers in the top wealth quintile benefit from the reform. This is largely driven by the observation that consumers at the top of the wealth distribution are older on average than consumers at the bottom of the wealth distribution. Moreover, the latter group is more likely to qualify for Medicaid, which in turn lowers their cost of eliminating Medicare. Finally, we find that about 70 percent of consumers in the second, third, and fourth labor earnings quintile benefit from the reform. In contrast, the majority of consumers in the first and fifth quintile of the earnings distribution are better off with Medicare.

\subsection{Eliminating Medicare and Medicaid}

The preceding subsection identified an important relation between Medicare and Medicaid. In particular, we found that the percentage of old consumers that qualified for Medicaid was higher in the economy without Medicare. A large share of the elderly therefore responded to the policy reform by substituting Medicaid for Medicare, which in turn lowered their cost of going through the transition. The substitutability between Medicare and Medicaid also implied that the elimination of Medicare would have limited long-run fiscal implications if the current Medicaid eligibility criteria were maintained. Given these findings, we therefore end this section with a brief analysis of the macroeconomic effects of eliminating both Medicare and Medicaid. Starting from the benchmark economy, we lower the Medicare and Medicaid insurance coverage rates to zero and study the effects as the economy transitions to its new steady state.

Eliminating both programs leads to a 37.8 percent surge in capital per capita as consumers accumulate assets to finance the higher cost of medical expenses throughout their life. This almost ninefold increase in capital compared to what we found when we only eliminated Medicare highlights Medicaid's significant insurance role in the economy. The combination of 11.0 percent higher wages and 10.0 percentage points lower payroll taxes raises labor supply and generates an increase in output per capita of 14.5 percent.

Table 7 showed that eliminating Medicare increases the percentage of expenses paid by private insurance plans from 12.0 to 15.7 percent. Eliminating Medicaid further increases this fraction to 43.2 percent. This shows that public insurance crowds out private insurance in the economy by discouraging consumers from purchasing insurance. Similar results are reported by Cutler and Gruber (1996), who estimate the extent of private insurance crowd-out following the 1987-1992 expansion of Medicaid eligibility to pregnant women and children.

Our estimates show that public spending declines by $\$ 777$ billion on impact when we eliminate Medicare and Medicaid, about 75 percent of the $\$ 1.03$ trillion the government spends on these programs in the benchmark economy. As the economy approaches the new steady state, we find that the reform leads to an $\$ 832$ billion annual reduction in fiscal spending. This additional long-run reduction in public expenditures can be attributed to spending on food stamps, which increases during the first years of the transition but eventually declines following the surge in saving, the last of which raises the relative cost of going on food stamps in the model.

Next, we examine the ex-ante welfare effect of the reform, and find that ex-ante welfare is higher in the economy without Medicare and Medicaid. In particular, we find that consumption has to increase by 7.8 percent in all periods and contingencies in the steady state with Medicare and Medicaid to make an unborn 
consumer under the veil of ignorance indifferent between the two steady states. That said, this measure fails to account for the costs of transiting between the steady states. It also abstracts from the reform's heterogeneous welfare effects on consumers of different types. After accounting for these costs, we find that eliminating Medicare and Medicaid lowers aggregate welfare, and that the per capita welfare loss of the reform is equivalent to at least a $\$ 29,500$ reduction in wealth in the initial steady state. As noted earlier, this measure binds for some consumers. That is, some consumers will be strictly better off in the initial steady state with Medicare and Medicaid even if they forfeit all of their current wealth. We find that the constraint binds for 37.4 percent of the population. Finally, we find that 19.4 percent of the population alive in the period of the reform is better off without both Medicare and Medicaid. That is, the majority of the population would not vote in favor of eliminating both programs. While our previous result showed that young consumers would benefit from the elimination of Medicare, we find that the majority of all age groups would be worse off if both programs were to be removed.

\section{Sensitivity analysis}

We have conducted a wide range of sensitivity analyses, and we find that our main results are robust. That is, the findings that aggregate ex-post welfare declines if we eliminate Medicare, that old consumers partially substitute Medicaid for Medicare, and that part of the reduction in government spending from eliminating Medicare is offset by higher spending on other social insurance programs are robust to alternative parameterizations of the model. We limit our discussion here to two robustness checks. First, we consider an alternative parameterization of the model where we lower the Medicare copayment parameter. Then we examine the implications of using median rather than weighted mean Medicaid income and asset limits. In both cases we recalibrate the model to match the same targets as in section 4. A comparison of the macroeconomic effects of eliminating Medicare under different parameterizations of the model is given in table 11 .

Lower Medicare copayment parameter The copayment parameter for Medicare was set to match the age-specific insurance distribution in the data. Here we consider an alternative parameterization of the model where we set the Medicare copayment parameter to match the average share of expenses paid by Medicare across individuals with Medicare as their primary insurance provider. Given data from the MEPS, we obtain a Medicare copayment parameter of 29.1 percent.

Lowering the Medicare copayment parameter from 50.0 to 29.1 percent increases the percentage of medical expenses paid by Medicare from 19.8 to 28.1 percent. This increase can be attributed to a reduction in the percentage of expenses paid out-of-pocket, by Medicaid, and by private insurance. Higher Medicare expenses translate into higher payroll taxes in the initial steady state of this economy. As a result, we find that eliminating Medicare leads to a 4.0 percentage points reduction in payroll taxes in this economy, compared to the 2.7 percentage points reduction in payroll taxes reported in section 5.1.

We find that our result regarding how much the government will save by eliminating the program is robust to this alternative parameterization of the model. Whereas the government saves 46 cents for every dollar it cuts on Medicare in the benchmark model, it saves 49 cents for every dollar it cuts on Medicare in this model. Our finding that 56.4 and 56.8 percent of the population alive in the period of the reform would benefit from the elimination of Medicare in this model and in the benchmark model, respectively, also shows that the welfare implications of eliminating Medicare are comparable in the two models. That said, using a 
lower Medicare copayment parameter further increases the elderly's cost of going through the transition. As a result, we find that the per capita welfare loss of the reform is equivalent to at least a $\$ 14,700$ reduction in wealth in the initial steady state under this parameterization of the model, compared to at least a $\$ 9,900$ reduction under the benchmark parameterization.

Median Medicaid income and asset limits We end this section by studying the effects of eliminating Medicare in a model with median rather than weighted mean Medicaid income limits. That is, we set the categorical income limit to match the 64.0 percent median categorical income limit across states, and set the medically needy income and asset thresholds to match the 50.5 percent and $\$ 2,000$ median medically needy income and asset limit across the states with a medically needy program.

Using median rather than weighted mean Medicaid eligibility limits increases the percentage of elderly that qualifies for Medicaid in the model, which in turn lowers their cost of going through the transition. As a result, we find that the aggregate welfare loss from eliminating Medicare is higher in the benchmark model than in the model with median Medicaid eligibility limits. In particular, we find that the per capita welfare loss of the reform is equivalent to at least a $\$ 9,500$ reduction in wealth in the initial steady state under this parameterization of the model, slightly less than the $\$ 9,900$ reduction reported in section 5.1. Next, we find that the majority of the population alive in the period of the reform would benefit from the elimination of Medicare under both parameterizations of the model. While 56.8 percent of the population would vote for the policy reform in the benchmark model, we find that 56.6 percent of the population would benefit from the elimination of Medicare in the model with median Medicaid eligibility thresholds. Lastly, our results show that the fiscal implications of the policy reform are similar in the two models. Recall from section 5.1 that the government saves 46 cents for every dollar it cuts on Medicare expenses. In comparison, we find that the government saves 44 cents for every dollar it cuts on Medicare in the model with median Medicaid eligibility limits.

\section{Conclusion}

This paper has developed an overlapping generations model to study the role of Medicare in the macroeconomy. We used the model to quantify the effects of an unexpected elimination of Medicare on macroeconomic aggregates, insurance enrollment, government spending, and welfare. We found that a large share of the elderly responded to the reform by substituting Medicaid for Medicare, which in turn increased spending on Medicaid from 3.6 to 5.3 percent of GDP. Spending on Social Security benefits also increased from 4.7 to 4.8 percent of GDP due to a rise in wages following an increase in capital. As a result, we found that the government saved only 46 cents for every dollar it cut on Medicare.

We then examined the welfare effects of the reform, and found that ex-ante welfare was higher in the steady state without Medicare. In particular, we found that consumption had to increase by 3.6 percent in all periods and contingencies in the steady state with Medicare to make an unborn consumer under the veil of ignorance indifferent between the two economies.

Lastly, we have examined the ex-post welfare effects of the reform on the current cohorts. Our estimates showed that the majority of young consumers would benefit from the policy change due to the reform's effect on wages and payroll taxes. The majority of the elderly, on the other hand, were better off in the economy with Medicare. After summing across all age brackets, we found that 56.8 percent of the population alive

in the period of the reform would benefit from the elimination of Medicare. Finally, we showed that the 
average welfare gain across the winners of the reform was considerably lower than the average welfare loss experienced by the remaining population. As a result, we found that the elimination of Medicare lowered aggregate welfare, and that the per capita welfare loss of the reform was equivalent to at least a $\$ 9,900$ reduction in wealth in the initial steady state.

We have also studied an alternative policy reform where we eliminated both Medicare and Medicaid. The elimination of both programs led to a surge in capital and labor supply, which in turn increased output per capita by 14.5 percent. It also resulted in a 31.2 percentage points increase in private insurance coverage and a 10.0 percentage points reduction in payroll taxes. Lastly, we found that the reform lowered aggregate ex-post welfare, and that only 19.4 percent of the population alive in the period of the reform was better off in the economy without Medicare and Medicaid.

This paper has abstracted from two channels that are likely to influence our results. First, we did not account for demographic changes in the model. In particular, we did not account for the projected increase in the old age dependency ratio, which will raise the future fiscal burden of Medicare. Second, the healthexpenditure-to-GDP ratio has risen steadily since the 1960s and is projected to continue to increase in the future. To overcome the future fiscal pressure from Medicare and Medicaid, the government will have to raise taxes, lower the public insurance coverage rates, or change the eligibility rules, an example of which would be to increase the age at which individuals can claim Medicare. We leave it to future work to address how our results regarding the macroeconomic effects of Medicare are affected by these channels.

We also leave it to future research to examine two additional extensions of our paper: optimal fiscal policy and a small open economy framework. The optimal fiscal policy approach can be used to identify ways to finance the transition from an economy with Medicare to an economy without Medicare where the new equilibrium is constrained Pareto optimal. Conesa and Garriga (2008) use this approach to study Social Security reforms and find that cohort-specific labor income taxes can be used to shift the welfare gains between present and future generations. Lastly, we considered a closed economy where accumulation of assets leads to an increase in the wage rate, which increases the welfare for an unborn consumer under the veil of ignorance. Future research should examine how our results would change if we instead considered a small open economy framework where the increase in accumulation of assets may not increase the wage rate. 


\section{References}

Attanasio, O., S. Kitao, and G. L. Violante (2010), "Financing Medicare: A General Equilibrium Analysis," in J. B. Shoven (ed.), Demography and the Economy, University of Chicago Press.

Bairoliya, N., D. Canning, R. Miller, and A. Saxena (2017), "The Macroeconomic and Welfare Implications of Rural Health Insurance and Pension Reforms in China," forthcoming in Journal of the Economics of Ageing.

Borella, M., M. De Nardi, and F. Yang (2017), "The Aggregate Implications of Gender and Marriage," forthcoming in Journal of the Economics of Ageing.

Castañeda, A., J. Díaz-Giménez, and J.-V. Ríos-Rull (2003), "Accounting for the U.S. Earnings and Wealth Inequality," Journal of Political Economy, 111: 818-857.

Chatterjee, S., D. Corbae, M. Nakajima, and J.-V. Ríos-Rull (2007), "A Quantitative Theory of Unsecured Consumer Credit with Risk of Default," Econometrica, 75: 1525-1589.

Conesa, J. C., and C. Garriga (2008), "Optimal Fiscal Policy in the Design of Social Security Reform," International Economic Review, 49: 291-318.

Conesa, J. C., and D. Krueger (1999), "Social Security Reform with Heterogeneous Agents," Review of Economic Dynamics, 2: 757-795.

Cutler, D. M, and J. Gruber (1996), "Does Public Insurance Crowd Out Private Insurance?," Quarterly Journal of Economics, 111: 391-430.

De Nardi, M., E. French, and J. B. Jones (2010), "Why Do the Elderly Save? The Role of Medical Expenses," Journal of Political Economy, 118: 39-75.

Finkelstein, A. (2007), "The Aggregate Effects of Health Insurance: Evidence from the Introduction of Medicare," Quarterly Journal of Economics, 122: 1-37.

Finkelstein, A., and R. McKnight (2008), "What Did Medicare Do? The Initial Impact of Medicare on Mortality and Out of Pocket Medical Spending," Journal of Public Economics, 92: 1644-1668.

French, E. (2005), "The Effects of Health, Wealth, and Wages on Labour Supply and Retirement Behaviour," Review of Economic Studies, 72: 395-427.

Hubbard, R., J. Skinner, and S. P. Zeldes (1994), "The Importance of Precautionary Motives in Explaining Individual and Aggregate Saving," Carnegie-Rochester Conference Series on Public Policy, 40: 59-125.

İmrohoroğlu, A., and K. Zhao (2017), "Intergenerational Transfers and China's Social Security Reform," forthcoming in Journal of the Economics of Ageing.

Jeske, K., and S. Kitao (2009), "U.S. Tax Policy and Health Insurance Demand: Can a Regressive Policy Improve Welfare?," Journal of Monetary Economics, 56: 210-221.

Jung, J., and C. Tran (2016), "Market Inefficiency, Insurance Mandate and Welfare: U.S. Health Care Reform 2010," Review of Economic Dynamics, 20: 132-159.

Krueger, D., and A. Ludwig (2016), "On the Optimal Provision of Social Insurance: Progressive Taxation Versus Education Subsidies in General Equilibrium," Journal of Monetary Economics, 77: 72-98. 
McGrattan, E. R., and E. C. Prescott (2017), "An Aggregate Model for Policy Analysis with Demographic Change," forthcoming in Journal of the Economics of Ageing.

Michaud, A., J. Nelson, and D. Wiczer (2017), "Vocational Considerations and Trends in Social Security Disability," forthcoming in Journal of the Economics of Ageing.

Palumbo, A. (1999), "Uncertain Medical Expenses and Precautionary Saving Near the End of the Life Cycle," Review of Economic Studies, 66: 395-421.

Pashchenko, S., and P. Porapakkarm (2013), "Quantitative Analysis of Health Insurance Reform: Separating Regulation from Redistribution," Review of Economic Dynamics, 16: 383-404. 
Table 1: Insurance parameters determined outside the model

\begin{tabular}{lllr} 
Parameter & Description & Source & Value \\
\hline & & & \\
$\chi_{P}$ & Private insurance copayment parameter & MEPS & 0.229 \\
$\chi_{E}$ & Employer insurance copayment parameter & MEPS & 0.229 \\
$\chi_{C A R E}$ & Medicare copayment parameter & MEPS & 0.500 \\
$\chi_{C A I D}$ & Medicaid copayment parameter & MEPS & 0.138 \\
$y^{c a t}$ & Categorical income limit & Kaiser Family Foundation & 0.197 \\
$y^{m n}$ & Medically needy income limit & Kaiser Family Foundation & 0.092 \\
$a^{m n}$ & Medically needy asset limit & Kaiser Family Foundation & 0.041
\end{tabular}

Table 2: Non-insurance parameters determined outside the model

\begin{tabular}{llrl} 
Parameter & Description & Source & Value \\
\hline$J$ & & & \\
$j_{r}$ & Maximum life span (100 years) & & \\
& Consumers receive SS and Medicare (66 years) & & 47 \\
$\alpha$ & Population growth rate & Conesa and Krueger (1999) & 0.011 \\
$\delta$ & Capital income share & Castañeda et al. $(2003)$ & 0.360 \\
$\gamma$ & Depreciation rate & French $(2005)$ & 0.059 \\
$\sigma$ & Consumption share in utility & & 0.574 \\
& IES $=0.5$ & & 2.742 \\
$\ell_{p}, \ell_{f}, \ell_{e}$ & Indivisible labor & & $0.225,0.300,0.375$ \\
$\xi(h)$ & Health-specific labor productivity & & $1,1,0$ \\
& Fraction of consumers with college degree & MEPS & 0.235
\end{tabular}

Table 3: Parameters determined jointly in equilibrium

\begin{tabular}{|c|c|c|c|}
\hline Parameter & Description & Target & Value \\
\hline$\theta$ & Total factor productivity & GDP pc $=1$ & 0.647 \\
\hline$\beta$ & Discount factor & Capital/output $=3$ & 0.927 \\
\hline$b_{c}$ & SS college replacement rate & Average SS benefits college $\approx \$ 14,200$ & 0.374 \\
\hline$b_{n c}$ & SS non-college replacement rate & Average SS benefits non-college $\approx \$ 11,900$ & 0.313 \\
\hline \multirow[t]{3}{*}{$\underline{c}$} & Consumption floor & Average food stamps $\approx \$ 1,300$ & 0.028 \\
\hline & Eligible for employer insurance & Share with private or employer $=0.508$ & 0.464 \\
\hline & Scale for health care costs & Health expenditure/output $=0.165$ & 1.803 \\
\hline$\sigma_{\eta}$ & Variance & Labor earnings Gini $=0.630$ & 4.051 \\
\hline$\eta_{t o p}$ & Productivity at the top & Labor earnings top 1 percent $=0.148$ & 24.657 \\
\hline$\pi_{t o p}$ & Probability at the top & Labor earnings top 10 percent $=0.435$ & 0.004 \\
\hline$\rho_{n}$ & Persistence & 2-year persistence: Bottom 80 percent $=0.940$ & 0.901 \\
\hline$\rho_{\text {top }}$ & Persistence at the top & 2-year persistence: Top 1 percent $=0.580$ & 0.775 \\
\hline
\end{tabular}


Table 4: Labor earnings distribution (percent)

\begin{tabular}{|c|c|c|c|c|c|c|c|c|c|}
\hline & \multicolumn{5}{|c|}{ Quintiles } & \multicolumn{3}{|c|}{ Top } & \multirow[b]{2}{*}{ Gini } \\
\hline & $1 \mathrm{st}$ & 2nd & 3rd & 4 th & 5 th & $90-95$ & 95-99 & 99-100 & \\
\hline Data & -0.40 & 3.19 & 12.49 & 23.33 & 61.39 & 12.38 & 16.37 & 14.76 & 0.63 \\
\hline Benchmark & 0.26 & 4.79 & 9.79 & 20.59 & 64.56 & 11.83 & 16.77 & 14.78 & 0.63 \\
\hline w/o Medicare & 0.42 & 5.20 & 9.82 & 20.44 & 64.13 & 11.75 & 16.65 & 14.67 & 0.62 \\
\hline
\end{tabular}

Table 5: Wealth distribution (percent)

\begin{tabular}{|c|c|c|c|c|c|c|c|c|c|}
\hline & \multicolumn{5}{|c|}{ Quintiles } & \multicolumn{3}{|c|}{ Top } & \\
\hline & 1st & 2nd & $3 \mathrm{rd}$ & 4 th & 5 th & 90-95 & 95-99 & 99-100 & Gini \\
\hline ata & -0.3 & 1.74 & 5.72 & 13.43 & 79.49 & 12.62 & 23.95 & 29.55 & 0.78 \\
\hline mark & 0.22 & 0.48 & 4.93 & 18.27 & 76.10 & 15.98 & 25.79 & 15.15 & 0.75 \\
\hline o Medicare & 0.22 & 0.46 & 4.43 & 17.80 & 77.09 & 16.33 & 26.26 & 15.24 & 0.75 \\
\hline
\end{tabular}

Table 6: Comparative statics: Economy with and without Medicare

Variable Without Medicare (percentage change from benchmark)

Table 7: Insurance distribution and medical expenses

\begin{tabular}{lrr|rr} 
& \multicolumn{2}{c|}{$\begin{array}{c}\text { Head count by main provider } \\
\text { (percent of population) }\end{array}$} & \multicolumn{2}{c}{$\begin{array}{c}\text { Medical expense } \\
\text { (percent of total medical expenses) }\end{array}$} \\
\cline { 2 - 5 } & Benchmark & Without Medicare & Benchmark & Without Medicare \\
Private & & & & \\
Employer & 33.6 & 15.1 & 12.0 & 15.7 \\
Self & 18.8 & 33.3 & 19.2 & 19.3 \\
Medicare & 18.2 & 26.1 & 22.9 & 0.0 \\
Medicaid & 16.4 & 0.0 & 19.8 & 32.3 \\
FS + MR & 5.0 & 20.8 & 22.1 & 4.1 \\
& & 4.7 & 4.0 &
\end{tabular}


Table 8: Fiscal implications

Spending (percent of GDP)

Benchmark Without Medicare

$\begin{array}{lll}\text { Medicare } & 3.3 & 0.0 \\ \text { Medicaid } & 3.6 & 5.3 \\ \text { Social Security } & 4.7 & 4.8 \\ \text { FS }+ \text { MR } & 0.6 & 0.6\end{array}$

Table 9: Ex-post welfare effects

\begin{tabular}{|c|c|c|c|}
\hline Variable & Votes in favor (percent) & $W E V^{1}$ (dollars) & $\overline{C E V}$ (percent) \\
\hline Entire population & 56.8 & $-9,900$ & -2.0 \\
\hline \multicolumn{4}{|c|}{ Winners and losers } \\
\hline Winners & 100.0 & 3,600 & 1.8 \\
\hline Losers & 0.0 & $-27,700$ & -7.0 \\
\hline \multicolumn{4}{|l|}{ Education } \\
\hline Non-college & 56.2 & $-9,300$ & -2.0 \\
\hline College & 58.6 & $-12,100$ & -1.8 \\
\hline \multicolumn{4}{|l|}{ Medical expenses } \\
\hline Low & 56.3 & $-10,300$ & -2.0 \\
\hline High & 57.5 & $-9,400$ & -2.0 \\
\hline Catastrophic & 61.8 & $-1,400$ & -1.2 \\
\hline \multicolumn{4}{|l|}{ Wealth (quintile) } \\
\hline $1 \mathrm{st}$ & 70.6 & 1,000 & -1.6 \\
\hline 2nd & 77.6 & 2,800 & 0.2 \\
\hline $3 r d$ & 71.8 & $-1,800$ & -0.3 \\
\hline 4 th & 51.9 & $-10,700$ & -2.7 \\
\hline 5 th & 14.2 & $-39,600$ & -5.2 \\
\hline \multicolumn{4}{|c|}{ Labor earnings (quintile) } \\
\hline $1 \mathrm{st}$ & 40.1 & $-16,600$ & -5.6 \\
\hline 2nd & 69.5 & $-4,500$ & -0.8 \\
\hline $3 \mathrm{rd}$ & 70.2 & -900 & 0.1 \\
\hline 4 th & 68.8 & $-6,000$ & -0.5 \\
\hline 5 th & 36.0 & $-21,400$ & -2.8 \\
\hline
\end{tabular}

Table 10: Medicaid and food stamps enrollment by health in steady state with Medicare (percent of population)

\begin{tabular}{lrr} 
Health & Medicaid & Food stamps \\
\hline & & \\
Low & 12.6 & 4.9 \\
High & 37.4 & 5.1 \\
Catastrophic & 28.0 & 44.1
\end{tabular}


Table 11: Comparative statics: Effect of eliminating Medicare under different parameterizations of the model

\begin{tabular}{llrrr} 
& Variable & Benchmark & Lower Medicare copay & Median Medicaid limits \\
\hline & & & & \\
$y$ & Output pc & 2.0 & 3.1 & 1.8 \\
$k$ & Capital pc & 4.4 & 7.1 & 4.0 \\
$h$ & Avg hours & 2.1 & 3.2 & 1.7 \\
$c$ & Consumption pc & 1.8 & 2.6 & 1.5 \\
$N$ & Effective labor pc & 0.7 & 1.0 & 0.6 \\
$w$ & Wage rate & 1.3 & 2.1 & 1.2 \\
& & & -2.5 \\
\hline$\tau$ & Tax rate & -2.7 & -4.0 & -0.3 \\
$r$ & Interest rate & -0.3 & -0.4 &
\end{tabular}


Figure 1: Medical expenses by age and health state (MEPS)

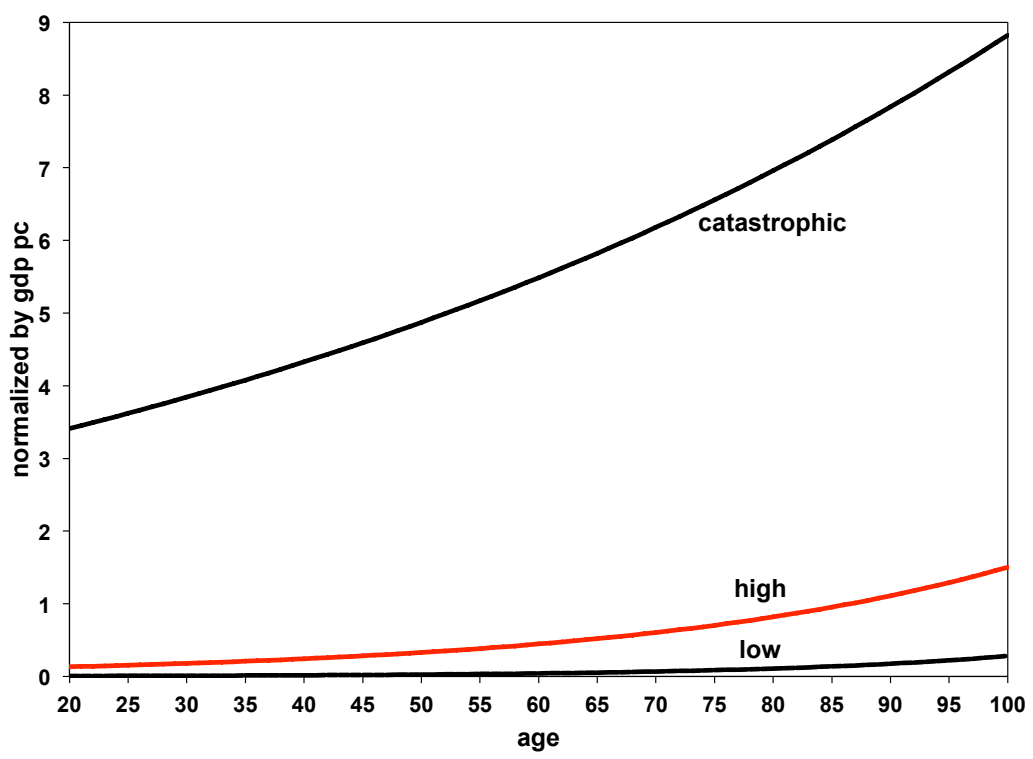

Figure 2: Medical expense risk by age (MEPS)

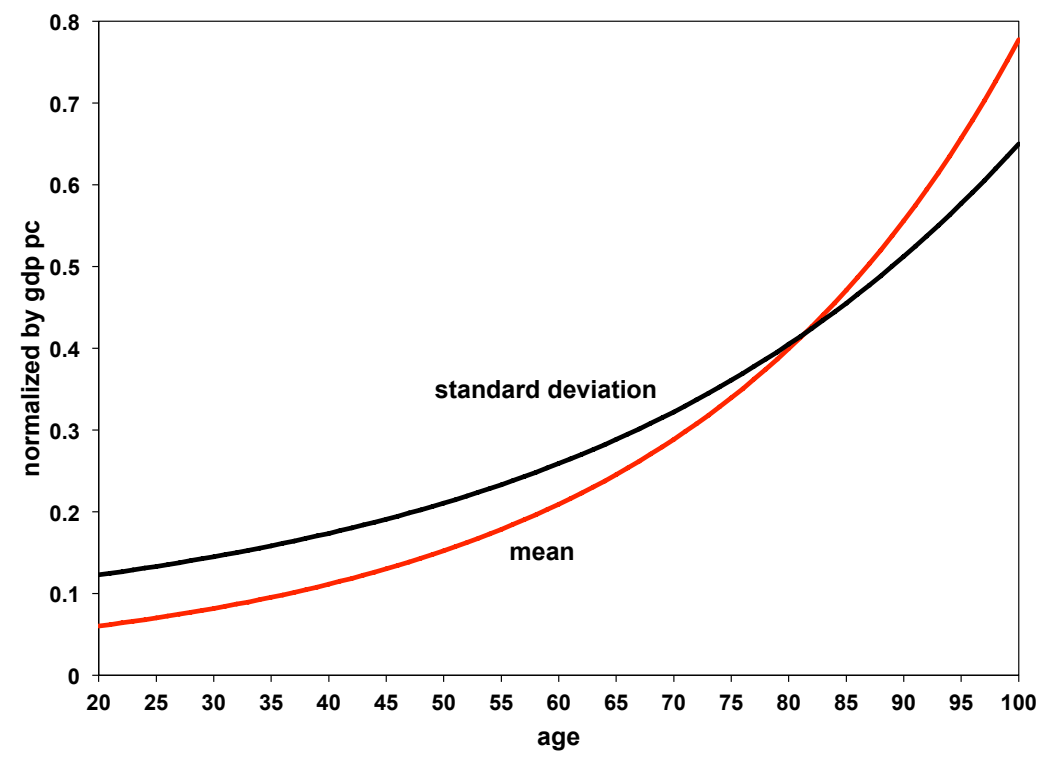


Figure 3: Distribution of medical expenses by age and provider
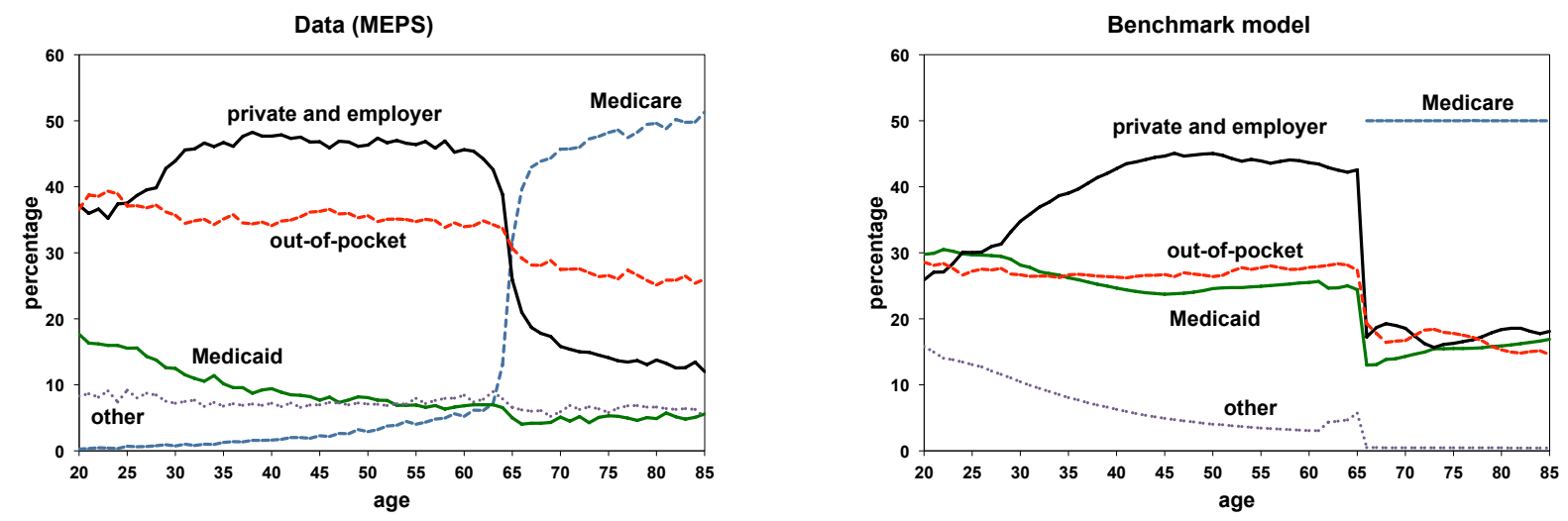

Figure 4: Medicaid enrollment by age

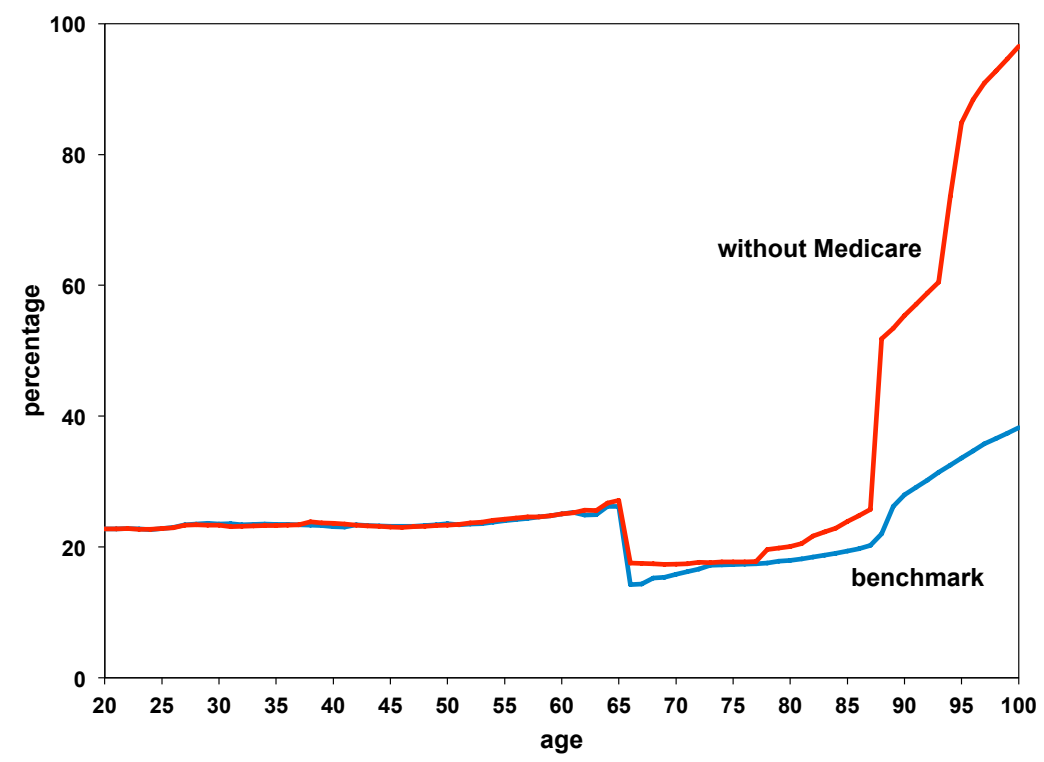


Figure 5: Transition from economy with Medicare to economy without: Aggregates

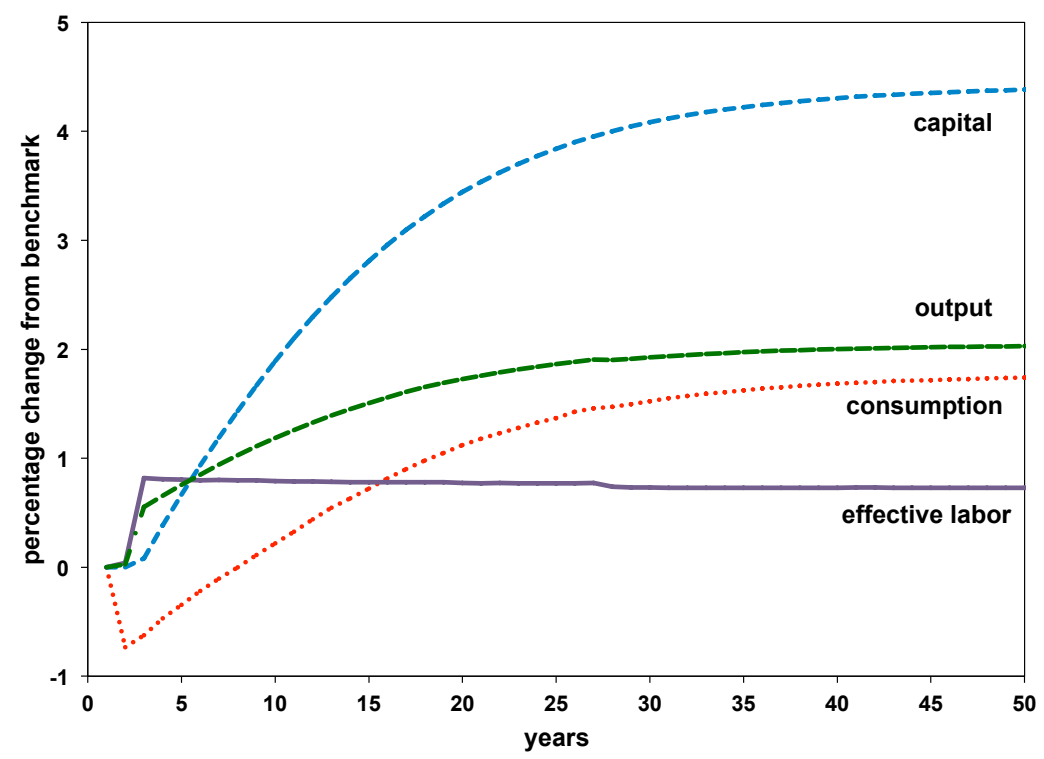

Figure 6: Transition from economy with Medicare to economy without: Ex-ante welfare on unborn consumer

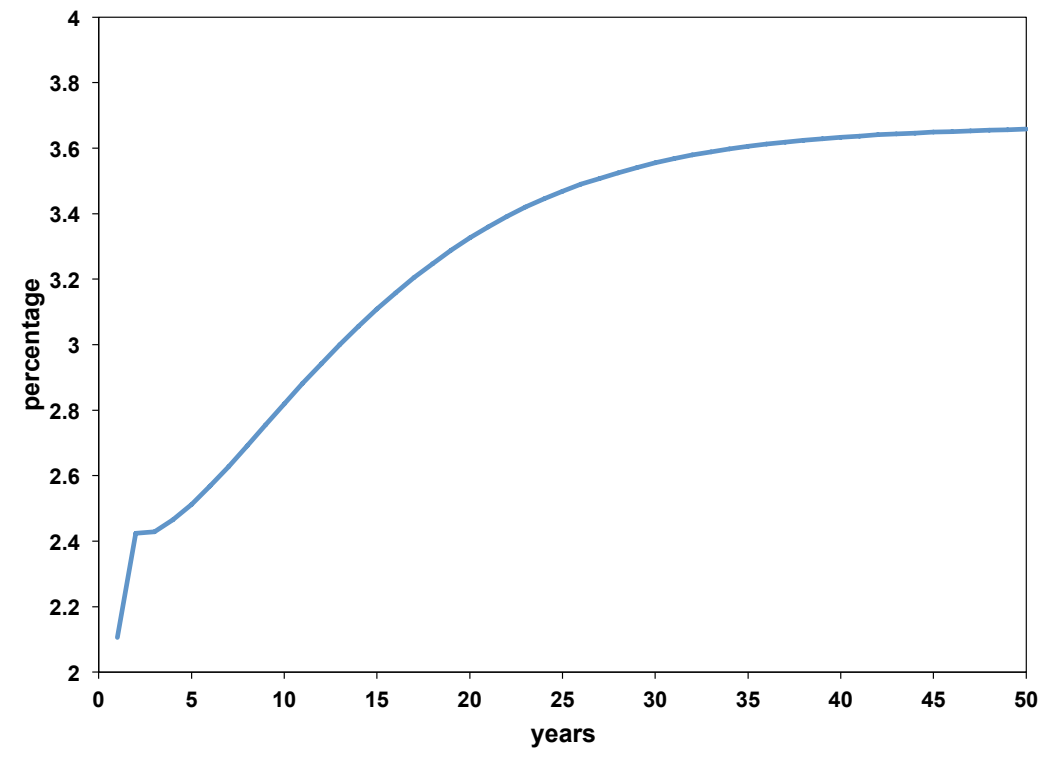


Figure 7: Percentage of votes in favor of reform by age

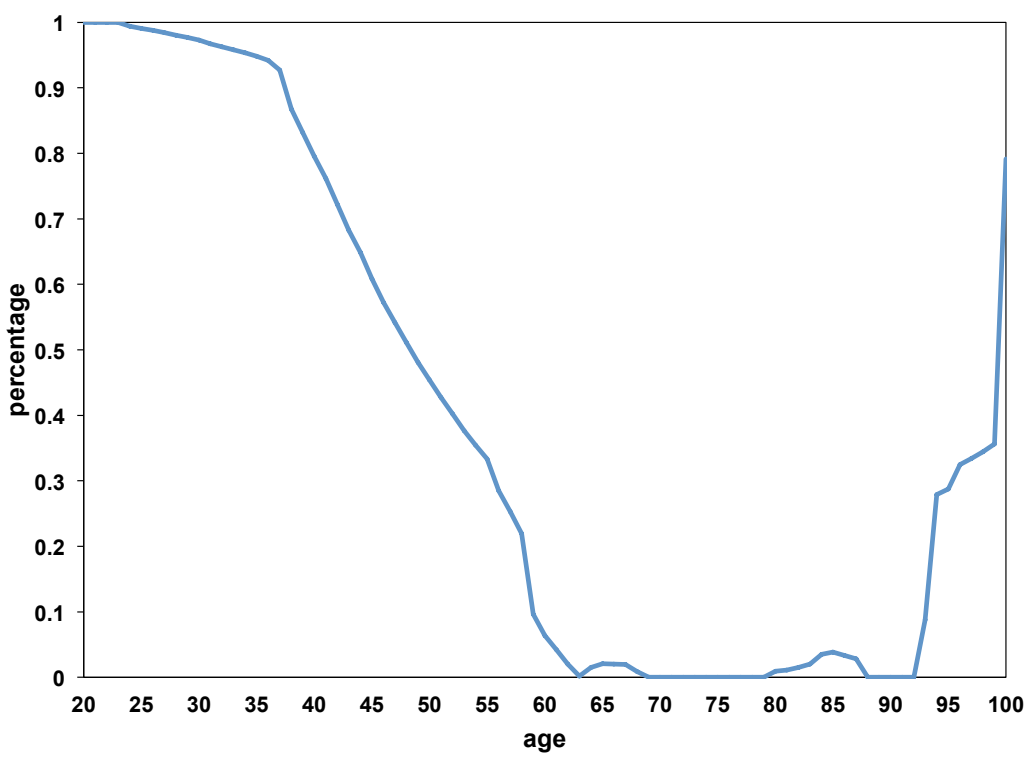

Figure 8: Percentage of votes in favor of reform by age and health

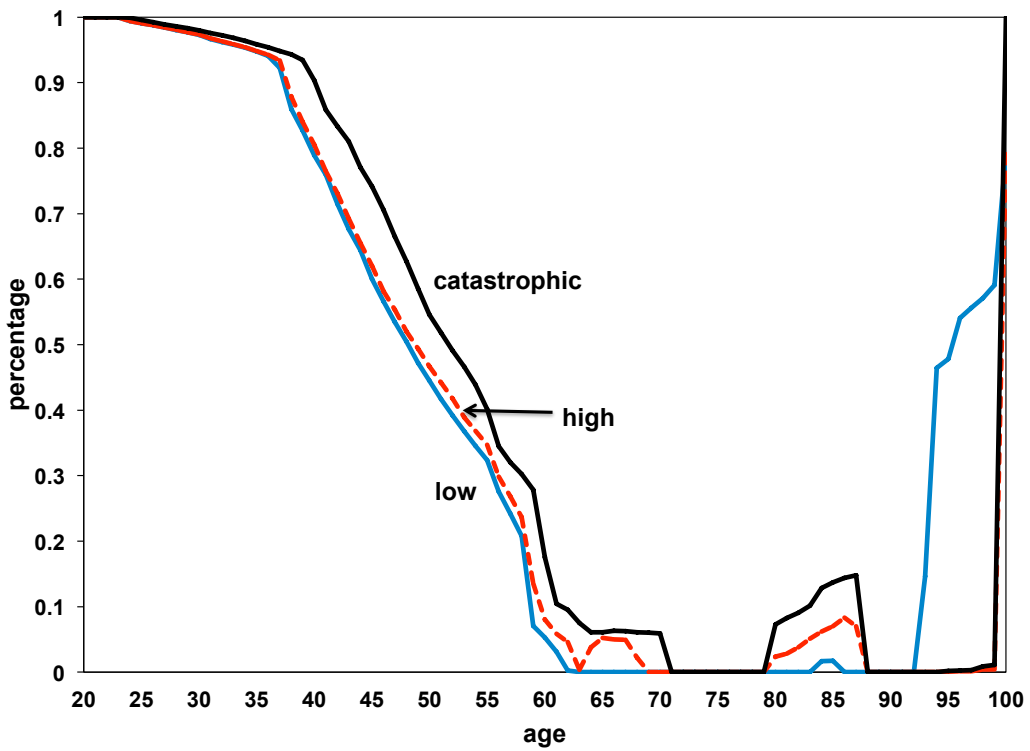

